Depth to magnetic basement

in the

ventura Basin area, California

by

Eureka Resource Associates, Inc.

U.S. Geological Survey

Open-File Report $82-879$

This report was prepared under contract to the U.S. Geological Survey and has not been reviewed for conformity with uSGS editorial standards and stratigraphic nomenclature. Opinions and conclusions expressed herein do not necessarily represent those of the USGS. Any use of trade names is for descriptive purposes only and does not imply endorsement by the usGS. 


\section{Depth to Magnetic Basement \\ in the \\ Ventura Basin Area, California}

By

Eureka Resource Associates, Inc.

2161 Shattuck Avenue

Berkeley, California

June 1978

For

Aerial Survey Incorporated

Salt Lake City, Utah 
Note by the U.S. Geological Survey

This report is an interpretation of data from an aeromagnetic map of the Ventura Basin, California (U.S. Geological Survey, 1980).

\section{Reference}

U.S. Geological Survey, 1980, Aeromagnetic map of the ventura Basin, ventura and Los Angeles Counties, California: U.S. Geological Survey Open-File Report $80-64$, scale $1: 62,500$. 
Plate 1 - . - . - Magnetic Model Based on Cross section D-D' of Nagle and Parker (1971)

Plate 2. . . . . . . Structural Cross Sections Beneath Magnetic Models 1 and 2

Plate 3 . . . . . . Structural Cross Sections Beneath Magnetic Models 3 and 4

(Plates are unbound)

Figure 1........ Cross section and Aeromagnetic survey Location Map. (Modified from Nagle and Parker, Figure 1, 1971) ..... Page 2 
INTRODUCTION

At the request of Aerial Surveys, Inc., Eureka Resource Associates, Inc. has interpreted aeromagnetic data to measure the depth to magnetic basement in Ventura Basin, southern California (Figure 1). Our interpretation is presented as four model cross sections (Plates 1, 2, and 3 [unbound]).

\section{METHOD OF ANALYSIS}

The great depths (perhaps as much as $16.5 \mathrm{~km}[55,000 \mathrm{ft}]$ of post-Jurassic sediments) and relatively high thermal gradients (approximately $30^{\circ} \mathrm{C} / \mathrm{km}$ ) of the ventura Basin led us also to consider the shape of the Curie point isotherm and the magnetic effects of thermal metamorphism of sediments in the construction of a model.

Flight line lengths were insufficient to determine the depth to basement using conventional inverse methods of calculation, so a two-dimensional modeling program (MAGNE2D) described by Joyner (1968) was used. Inadequate data edge also made direct calculation of the depth to the Curie point isotherm impossible using the aeromagnetic data, so it was inferred from magnetic modeling and from the Subsurface Temperature Map of North America (AAPG and USGS, 1976).

Metamorphic effects were estimated from the pressure-temperature metamorphic facies diagram of Hietanen (1967) and were modeled upon other Curie point studies done by Eureka. The objective of the study was to estimate depth to basement, not lithology, so we have concentrated on matching the space frequency of the longer spatial wave length anomalies and only minor attention has been given to matching amplitudes of the high space frequency (shallower) anomalies. 
Aeromagnetic data were collected along 33 north-south flight lines and 3 east-west tie lines in the survey area at 1000 foot terrain clearance (semidrape). These data were used by Aerial Surveys, Inc. to prepare a contour map of the total intensity residual magnetic field after correction for diurnal variations and subtraction of the International Geophysical Reference Field updated to November 1977. Four north-south profiles were selected for magnetic modeling due to the proximity of published geologic cross sections (Nagle and Parker, 1971) and their spatial relationships to major geologic structures within the survey area. Residual magnetic anomaly values were digitized along these four lines and were used to prepare the magnetic profiles which formed a basis for the magnetic modeling.

As a preliminary step, we selected profile D-D' of Nagle and parker (1971, Figure 17) and, assuming that the sespe redbeds, Miocene volcanics, and crystalline basement were inductively magnetized, calculated magnetic profiles that would be due to the approximate geometries shown in their cross section. Even after postulating the existence of a large intrusive body in the southern part of the Western Santa Monica Basin, agreement between the calculated and observed magnetic anomalies was very poor (Plate 1 ).

our subsequent models were based upon both structural cross sections and a depth-to-basement contour map published by Nagle and Parker. Generally good agreement between observed and computer anomalies was obtained by making simple modifications to both the geometries and magnetic susceptibilities of the bodies shown in their cross sections, adding bodies whose presence was apparent in the magnetic data, but not indicated on their cross sections, and by considering thermally related effects, such as those attributable to thermal gradient variations. 


\section{RESULTS}

The results of our modeling are shown graphically as structural cross sections (Plates 1,2 , and 3 ). A heavy dashed line indicating the basement shape as inferred from Figure 13 of Nagle and Parker (1971) has been shown for comparison. Reasonable agreement exists between the vertical block boundary model described by Nagle and Parker (1971) and the observed magnetic data, but the depth to magnetic basement in the deeper sedimentary basins, such as the Santa Clara Trough, was much shallower than the depth to basement indicated in their paper. Given the relatively high thermal gradient of the region, our results indicate that greenschist facies metamorphism may be present in the post-Eocene rocks in the deeper basins, and that considerable stratigraphic uncertainty exists as to the meaning of magnetic basement in this region.

In addition, we found that in order to model the medium and short wavelength anomalies which are clearly present in the observed magnetic field, it was necessary to introduce magnetic bodies at intermediate and shallow depths which were not shown by Nagle and Parker and are not mapped at the surface. We interpret these bodies as being associated with Miocene intrusive and volcanic activity, which appears to have been extensive within much of the study area.

It is noted that along our profile number 1 , although there was a good agreement between the shapes and amplitudes of the observed and calculated anomalies, the calculated magnetic profile was about 70 gammas higher than the observed profile along nearly the entire length of the profile. We attribute this "DC" shift as being the result of a significant change in the curie point isotherm boundary occurring off our profile. 
Bhattacharyya, B. K., and Leu, L., 1975, Analysis of magnetic anomalies over Yellowstone National Park; mapping of Curie point isothermal surface for geothermal reconnaissance: Journal of Geophysical Research, v. 80 , pp. $4461-4465$.

Hietanen, A., 1967, On the facies series in various types of metamorphism: Journal of Geology, v. 75, pp. 187-214.

Joyner, W. B., 1968, Two-dimensional magnetic profiles, program no. W9205: U.S. Geological Survey, Computer Center Division, Washington, D.C., 13 pp. Nagle, H. E., and Parker, E. S., 1971, Future oil and gas potential of onshore Venture Basin, California: IN Future Petroleum Provinces of the United States--Their Geology and Potential, ed. I. H. Cram, American Association of Petroleum Geologists, Memoir 15, Tulsa, Oklahoma, pp. 254-297. 